\title{
Aderência à técnica na psicoterapia psicanalítica: estudo preliminar
}

\author{
Adherence to technique in psychoanalytic \\ psychotherapy: a preliminary study
}

Marina Bento Gastaud', Camila Piva da Costa', Carolina Stopinski Padoan', Daniela Berger', Daniela Bergesch

D’Inca01, Daniela Valle Krieger', Letícia Dornelles Lacerda', Michelle Aline Volkmann Camozzato

Prezado editor,

Classicamente, o treinamento em psicoterapia psicanalítica está baseado em um tripé proposto por Freud para formação de psicanalistas: aprendizado teórico, supervisão clínica e análise/psicoterapia psicanalítica pessoal. Por ser uma atividade realizada de forma isolada, sem que o professor/supervisor esteja presente durante a sessão, não há garantia de que esse aprendizado esteja sendo utilizado na prática clínica do terapeuta em formação. Ademais, a aplicação da técnica psicanalítica também depende de características do paciente: quando o paciente não apresenta capacidade de insight e de abstração ou quando necessita de contenção por parte do terapeuta, o terapeuta tende a utilizar técnicas mais diretivas, abordagens de apoio ou técnicas mistas em sua prática ${ }^{1,2}$. Diante dessas constatações, questiona-se: os psicoterapeutas de um ambulatório de psicoterapia psicanalítica (Contemporâneo - Instituto de Psicanálise e Transdisciplinaridade, Porto Alegre/RS) de fato atuam psicanaliticamente com seus pacientes? Os pacientes dessa instituição propiciam o uso da técnica psicanalítica durante seus atendimentos? O ambulatório em questão agrega uma escola de psicanálise que forma especialistas em psicoterapia psicanalítica com base no tripé acima mencionado.

Decidiu-se, então, submeter à análise de pares de juízes 118 sessões dialogadas de pacientes adultos atendidos no referido ambulatório nos últimos cinco anos, cedidas pelos terapeutas (67 sessões, 56,8\%) e seus supervisores (51 sessões, 53,2\%). Quinze terapeutas e 81 pacientes estão representados nessas sessões. As sessões foram avaliadas por oito juízes (psicólogos especialistas em psicoterapia psicanalítica), independentemente, após treinamento.

Utilizou-se o Instrumento para Avaliação de Sessões Psicanalíticas (IASP), o qual apresenta boa confiabilidade e é composto pelos itens: neutralidade do terapeuta, tipo de intervenções utilizadas, uso de interpretações, uso da teoria psicanalítica para compreensão do material, criação de espaços reflexivos e relação terapeuta-paciente ${ }^{3,4}$. A pontuação final da sessão pode variar de 0 a 25 pontos, e sessões com pontuações iguais ou superiores a 13 são consideradas psicanalíticas. O instrumento não mensura a qualidade da sessão e a adequação das intervenções do terapeuta; não há necessariamente correlação entre a aderência à técnica e a qualidade da sessão.

Das 118 sessões analisadas, houve concordância em que 106 delas seriam psicanalíticas e que duas não seriam; não houve concordância quanto às demais 10 sessões. Ajustando para

1 Instituto de Psicanálise e Transdisciplinaridade, Departamento de Pesquisa do Contemporâneo.

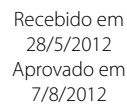

Endereço para correspondência: Marina Bento Gastaud Instituto de Psicanálise e Transdisciplinaridade, Departamento de Pesquisa Rua Comendador Caminha, 312/205 - 90430-030 - Porto Alegre, RS Telefone: (55 51) 3346-1664

E-mail: marinagastaud@hotmail.com 
a alta prevalência de sessões consideradas psicanalíticas, foi calculada a medida PABAK (prevalence-adjusted and bias-adjusted kappa), conforme proposto por Byrt et al. ${ }^{5}$. A concordância entre os juízes foi considerada alta (PABAK $=0,831 / p$ $=0,009$ ).

Assim, foi possível concluir que, nesse ambulatório, a técnica predominantemente utilizada corresponde ao modelo psicanalítico. Tentando favorecer o acesso às mais variadas sessões, de forma que fossem representativas dos atendimentos, optamos por coletar as sessões sem identificação do terapeuta e do paciente. Assim, não foi possível, neste estudo preliminar, estabelecer associações entre a aderência à técnica psicanalítica e as características dos pacientes e terapeutas envolvidos nesse atendimento, passos seguintes deste estudo ainda em andamento.

Assim, há indícios de que é possível aderir à técnica psicanalítica em settings institucionais (não apenas em consultórios particulares) e de que o ensino da psicoterapia psicanalítica baseado no tripé é suficiente para transmitir a técnica aos terapeutas.

\section{REFERÊNCIAS}

1. Gabbard G. Psiquiatria psicodinâmica - na prática clínica. Porto Alegre: Artmed; 2006.

2. Serralta F, Pole N, Nunes ML, Eizirik C, Olsen C. The process of change in brief psychotherapy: effects of psychodynamic and cognitive-behavioral prototypes. Psychother Res. 2010;20(5):564-75.

3. Hauck S, Crestana T, Mombach C, Almeida E, Eizirik C. Pesquisa em psicanálise e psicoterapia psicanalítica: um novo instrumento para avaliação de aderência à técnica em estudos de efetividade. Rev Bras Psiquiatr. 2008;30(3):290-301.

4. Almeida E. Criação e aplicação de instrumento para verificação de aderência à técnica psicanalítica em sessões de psicoterapia [dissertação]. Porto Alegre: Universidade Federal do Rio Grande do Sul, Programa de Pós-Graduação em Ciências Médicas, Psiquiatria; 2010.

5. Byrt T, Bishop J, Carlin JB. Bias, prevalence and kappa. J Clin Epidemiol. 1993;46(5):423-9. 